\title{
Peroxisome Proliferator-Activated Receptors (PPARs) Activation as Therapeutic Targets in Skin Inflammation
}

\author{
Akihiro Aioi ${ }^{1,2^{*}}$ \\ ${ }^{1}$ Griffith Institute for Drug Discovery, Griffith University, Nathan, Queensland 4111, Australia, a.aioi@griffith.edu.au \\ ${ }^{2}$ SPTM R\&D Australia, Nathan, Queensland 4111, Australia
}

\section{ABSTRACT}

Peroxisome proliferator-activated receptors (PPARs) are fatty acid activated transcription factors that belong to the nuclear hormone receptor family. They are initially known as transcriptional regulators of lipid and glucose metabolism, although further evidence has also been accumulated for other functions. Due to the nature of all PPAR isotypes which are expressed and exert effects by regulating the functions of cell types residing and infiltrating in the skin, PPARs represent a major research target for the understanding and treatment of many skin diseases. Atopic dermatitis (AD) is a chronic and relapsing disease characterized by skin barrier dysfunction and immune dysregulation. Skin barrier disturbance is one of the exacerbation factors of $\mathrm{AD}$, due to facile penetration of molecules such as antigens. From the aspect of immune dysregulation, innate and acquired immunity including cell proliferation, cell differentiation, and cytokine network are involved in the pathogenesis. In this review, the role of PPAR in AD and the possibility of its agonist for the treatment of AD are discussed.

Keywords: Peroxisome Proliferator-activated Receptors; Skin; Inflammation; Atopic Dermatitis

\section{Introduction}

PPARs are classified three different isoforms termed $\operatorname{PPAR} \alpha, \operatorname{PPAR} \beta / \delta$ and $\operatorname{PPAR} \gamma^{[1,2]}$. Initial studies demonstrated that PPARs are pivotal participants in the regulation of energy homeostasis by modulating glucose and lipid metabolism and transportation ${ }^{[3]}$, and then subsequent studies have shown that PPARs regulate in other cellular functions such as cell proliferation, cell differentiation, apoptosis and inflammation. Because all PPAR isotypes are expressed ${ }^{[4]}$ and exert effects by regulating the functions of cell types residing and infiltrating in skin, PPARs represent a major research target for the understanding and treatment of many skin diseases. Atopic dermatitis (AD) is a chronic and relapsing disease. AD is characterized skin barrier dysfunction and immune dysregulation. A typical characteristic of $\mathrm{AD}$ is xerosis which affects lesional and non-lesional skin areas, due to increased transepidermal water loss. This skin barrier disturbance exacerbates $\mathrm{AD}$, due to facile penetration of high molecules such as antigens ${ }^{[5]}$. Thus, the application of emollients is one of the basic treatments to support skin barrier function and allow hydration of the skin as conservative treatments ${ }^{[6]}$. Immune dysregulation occurs in both innate immunity and acquired immunity. The innate immunity is presented in the epidermis as the front line defense against infection. Antimicrobial peptides (AMPs), directly kill a broad spectrum of microbes, are secreted from keratinocytes and activated to respond immediately after microbial invasion. Although it is supposed that $\mathrm{AD}$ patients have a higher prevalence of infection with bacteria, fungi, and viruses due to skin barrier disruption, the defects of innate immune system are demonstrated previously ${ }^{[7]}$. Regarding dysregulation of acquired immunity, $\mathrm{AD}$ is originally regarded as a Th2-mediated disease because of the systemic elevation of Th2 cytokines with increased IgE levels and eosinophilia in the acute phase ${ }^{[6,8]}$. However, Th1 cytokines are detected in chronic AD, suggesting that Th1 cytokines are involved in the maintenance of chroic

Copyright (C) 2020 Akihiro Aioi

doi: 10.24294/ti.v4.i2.1063

EnPress Publisher LLC.This work is licensed under the Creative Commons Attribution-NonCommercial 4.0 International License (CC BY-NC 4.0). http://creativecommons.org/licenses/ by/4.0/ 
$\mathrm{AD} \operatorname{skin}^{[8,9]}$. Additionally, a study has reported that number of Th17 cells is significantly increased in $A D$ patients ${ }^{[10]}$. Thus these alternative concepts in $\mathrm{AD}$ should be addressed. Tacrolimus mainly acts on both Th1 and Th2 cells and then IFN- $\gamma$, IL-2, IL-4 and IL-5 are potently inhibited by tacrolimus ${ }^{[11]}$. Moreover, treatments with several monoclonal antibodies for AD are clinically applied or the clinical trials are underway ${ }^{[12-14]}$. In this review, the role of PPAR in AD and the possibility of its agonist for the treatment of $\mathrm{AD}$ are discussed.

\section{Peroxisome prolifera- tor-activated receptors}

PPARs are fatty acid activated transcription factors that belong to the nuclear hormone receptor family. They are initially known as transcriptional regulators of lipid and glucose metabolism, although further evidence has also accumulated for their other functions. Three PPAR isotypes, PPAR- $\alpha$, PPAR- $\beta / \delta$ and PPAR- $\gamma$, encoded by separate genes, have been identified in vertebrates. The expression of each isotype exhibits distinct tissue distribution reflecting their functions ${ }^{[15]}$. The highest expression of PPAR- $\alpha$ is found in liver, and preferentially expressed in metabolically active tissues including kidney, heart, skeletal muscle and brown fat ${ }^{[15-17]}$. PPAR $-\beta / \delta$ is expressed in a wide range of tissues such as brain, kidney, heart and skin $^{[18,19]}$. PPAR- $\gamma$ is expressed in heart, skeletal muscle, colon, intestines, kidney, pancreas and spleen. In human skin, all PPAR isotypes are expressed ${ }^{[4]}$. In skin, PPAR isotypes show the different expression pattern. PPAR $-\beta / \delta$ is ubiquitously present throughout the epidermis while the expression of PPAR- $\alpha$ and $-\gamma$ increase along with the differentiation of keratinocytes ${ }^{[20]}$. Ligands of PPARs comprise long chain polyunsaturated fatty acid (Table 1). For example, $\alpha$-linoleic acid, docosahexaenoic acid, arachidonic acid metabolites, and leukotrienes are the well-known endogenous ligands for PPARs. Many synthetic ligands for PPARs have been developed. Of them, fabric acid derivatives, dual-selective agonists for PPAR- $\alpha$ and $-\gamma$, and thiazolidinedione and derivatives, single-selective agonists for PPAR- $\gamma$, are successfully used in treatments of cardiovascular diseases and diabetes mellitus type $2^{[21,22]}$. However, any ligand for PPARs has not been clinically applied for the treatments of skin diseases. Previous studies have demonstrated underlying mechanisms in PPARs actions ${ }^{[23]}$. Once PPARs bind to their ligands, they form heterodimers with the retinoid $\mathrm{X}$ receptor (RXR), followed by direct binding to DNA response element, termed PPAR response elements (PPREs), located in the promotor regions of target genes ${ }^{[24-26]}$. Binding of ligand leads to the recruitment of coactivator complexes which modify chromatin structure and facilitate assembly of the general transcriptional machinery to the promoter ${ }^{[27]}$. This transactivation induces the expression of target genes, involved in PPARs functions (Figure 1).

\begin{tabular}{|c|c|c|c|c|c|c|c|}
\hline \multirow[b]{2}{*}{ Ligand } & \multicolumn{3}{|c|}{ Single-selective } & \multirow[b]{2}{*}{ Ligand } & \multicolumn{3}{|c|}{ Dual-selective } \\
\hline & PPAR- $\alpha$ & PPAR- $\beta / \delta$ & PPAR- $\gamma$ & & PPAR- $\alpha$ & PPAR- $\beta / \delta$ & PPAR- $\gamma$ \\
\hline 15-deoxy-D-12,14-PGJ ${ }_{2}$ & & & + & 9-HODE & + & & + \\
\hline Leukotrien $\mathrm{B}_{4}$ & + & & & 13-HODE & + & & + \\
\hline $\mathrm{PGA}_{1}$ & & + & & 15-HETE & + & & + \\
\hline $\mathrm{PGA}_{2}$ & & + & & Linoleic acid & & + & + \\
\hline $\mathrm{PGD}_{2}$ & & + & & Palmitic acis & + & + & \\
\hline $\mathrm{PGI}_{2}$ & & + & & Eicosapentanoic acid & & + & + \\
\hline 8(S)-HETE & + & & & Clofibrate & + & & + \\
\hline Oleic acid & + & & & Fenofibrate & + & & + \\
\hline Oleoylethanolamide & + & & & WY14643 & + & & + \\
\hline Thiazolidinediones & & & + & Ibuprofen & + & & + \\
\hline Fmoc-leucine & & & + & Indomethacin & + & & + \\
\hline Sulindac & & & + & Fenoprofen & + & & + \\
\hline GW0742 & & + & & Farglitazar & + & & + \\
\hline GW1929 & & & + & GW2331 & + & & + \\
\hline GW2570 & & & + & GW2433 & + & + & \\
\hline GW7845 & & & + & GW409544 & + & & + \\
\hline GW9578 & + & & & & & & \\
\hline GW501516 & & + & & & & & \\
\hline
\end{tabular}

HETE: hydroxyeicosatetraenoic acid, HODE: hydroxyoctadecadienoic acid, PG: prostaglandis

Table 1. Endogenous and synthetic ligands of PPARs 

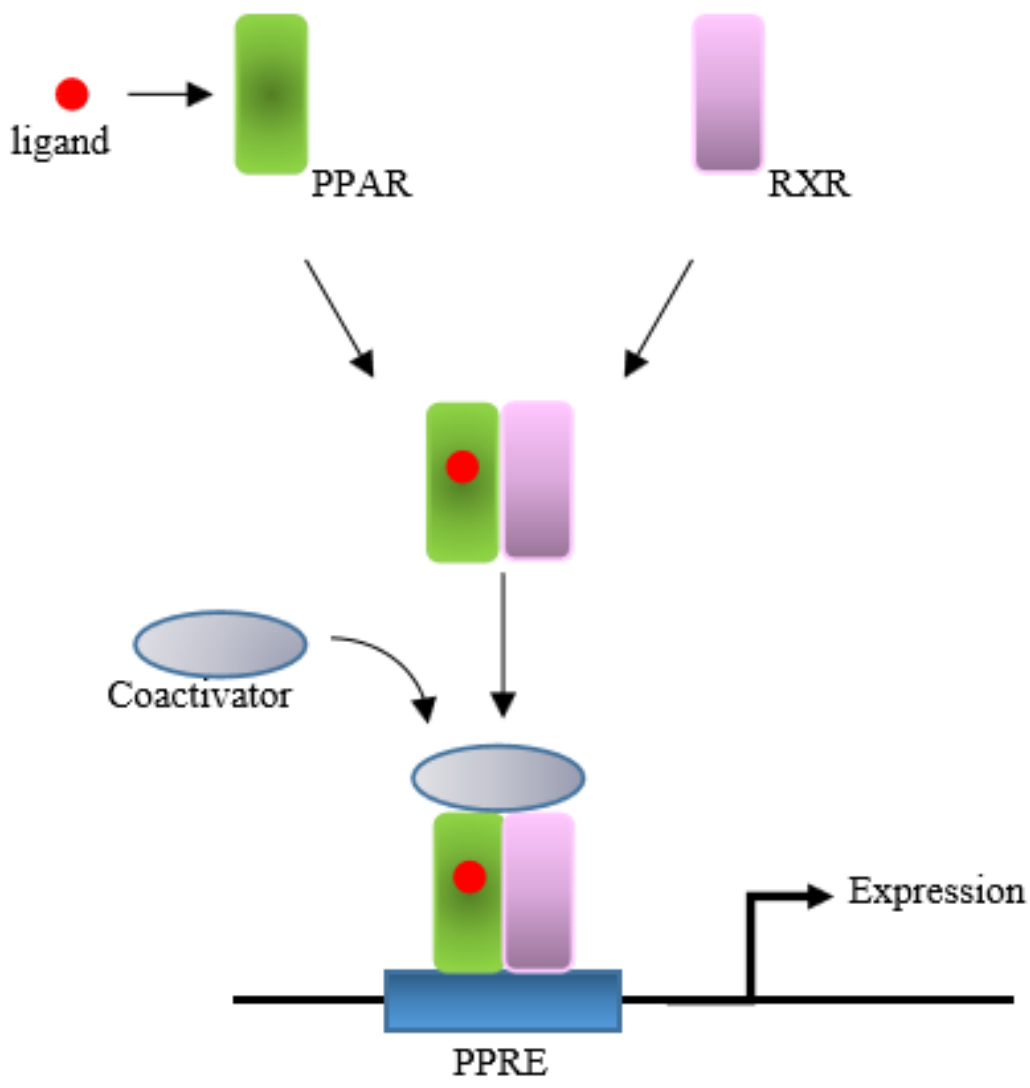

Figure 1; Mechanism of gene expression by PPAR activation. Specific ligands-activated PPARs form hetrodimers with retinoid $\mathrm{X}$ receptors (RXRs) and recruit cofactors. The complexes then modulate DNA transcription by binding to peroxisome proliferator response element (PPRE) in the promoter region of target genes.

\section{Roles of PPARs in inflammation}

Inflammation evoked by detrimental stimuli is a protective response in order to maintain homeostasis. Because innate immunity is considered as the first line of host defense against onset of harmful stimuli, immune cells such as macrophages, dendritic cells, mast cells, lymphocytes and neutrophils play crucial roles in complicated inflammation response. Apart from immune cells, non-immune cells such as keratinocytes, fibroblasts, epithelial cells and endothelial cells contribute the response as well ${ }^{[28,29]}$. In skin, once inflammatory stimuli are recognized by pattern-recognition receptors on the plasma membrane, inflammatory cytokines (e. g. TNF- $\alpha$, IL-1 $\beta$, IL-6) released from keratinocytes, fibroblasts and dendritic cells induce mediators during autocrine and paracrine signaling, followed by progression of the sophisticated inflammation process. Leukocyte adhesion, extravasation and migration to the inflammatory site are important events in leukocyte recruitment. Vascular cell adhesion molecule 1 (VCAM-1) and intercellular adhesion molecule 1 (ICAM-1) play pivotal roles in leuko- cyte adhesion and their expression is the consequence of stimulation by TNF- $\alpha$ and IL-1, while they are not present on quiescent endothelial cells ${ }^{[30]}$. On the other hand, IL-8, which is induced by TNF- $\alpha$, leads leukocyte, especially neutrophil, to migrate along a chemotactic gradient to the inflammatory site ${ }^{[31]}$. The initial demonstration of a regulatory function of PPAR- $\alpha$ in inflammation signaling was obtained in PPAR- $\alpha$-deficient mice that display an exacerbated response to inflammatory stimuli ${ }^{[32]}$. Consequently, intensive studies on the effects of PPAR activators on inflammatory responses have been revealed that all of PPAR isotypes exert distinct and overlapping anti-inflammatory effects ${ }^{[33-40]}$. The effects of PPARs activation on inflammatory molecules are listed in Table $\mathbf{2}^{[39,41]}$. Previous studies reported that a crosstalk between PPARs and transcription factors mediating inflammatory signaling including C/EBP, STAT, AP-1 and NF- B and proposed that five mechanisms of PPAR-mediated transrepression; i) direct interaction, ii) induction of $\mathrm{I} \kappa \mathrm{B} \alpha$, iii) regulation of kinase activity, iv) coactivator competition and v) co-repressor interaction ${ }^{[27,39,42]}$. The 
reduction of IL-1-stimulated IL-6 production from human smooth muscle cells by fenofibrate is caused by the repression of c-Jun, a component of AP-1, and NF- B-induced transcription of the human IL-6 promotor. This transcription interference occurs independent to the promotor context. Furthermore, in vitro protein-protein interaction assay showed fibrate-activate PPAR- $\alpha$ binds directly to c-Jun and NF- $\kappa$ B (Figure 2a) ${ }^{[43]}$. Another study demonstrated a distinct mechanism that fenofibrate induces the expression of $\mathrm{I} \kappa \mathrm{B}$, which inhibits NF- $\kappa \mathrm{B}$ by masking the nuclear localization signals of NF- $\kappa \mathrm{B}$ proteins and keeping them sequestered in an inactive state in the cytoplasm, in human aortic smooth muscle cells and hepatocytes, accompanied with a decrease in NF- $\kappa B$ DNA binding activity ${ }^{[44]}$. This suggests that PPAR activation inhibits NF- $\kappa B$ DNA binding by $\mathrm{I} \kappa \mathrm{B}$ induced by PPAR activation (Figure $2 \mathbf{b}$ ). In mice colon inflammation, troglitazone reduces $\mathrm{TNF}-\alpha$ and IL-1 $\beta$ mRNA levels, accompanied with reduction of NF- $\kappa \mathrm{B}$ DNA binding activity, c-Jun NH2-terminal kinase (JNK), and p38 activities ${ }^{[45]}$. Oxidative stress-induced production of TNF- $\alpha$ and IL- $1 \beta$ is reduced in PPAR- $\gamma$ overexpressing $\mathrm{Ad} / \mathrm{PPAR} \gamma \mathrm{C} 2 \mathrm{C} 12$ cells, compared to $\mathrm{Ad} / \mathrm{LacZ} \mathrm{C} 2 \mathrm{C} 12$ cells. At the same time, phosphorylation of ERK1/2 and p38 is inhibited in Ad/PPAR $\gamma$ C2C12 cells, concomitant with inhibition of NF- $\mathrm{BB}$ translocation from cytosol to nucleus ${ }^{[46]}$. Likewise, Shi and the colleagues demonstrated that alline, a potent PPAR- $\gamma$ activator, ameliorates LPS-induced production of iNOS, IL-1 $\beta$, IL-6 and TNF- $\alpha$ from RAW264.7 cells through the reduced phosphorylation of ERK1/2, JNK and p38, suggesting that PPAR- $\gamma$ activation regulates MAPKs activity $^{[47]}$. These suggest PPAR activation attenuates inflammatory response through regulation of protein kinase activity (Figure 2c). Several members of the nuclear receptor family including PPARs and RXR require coactivator such as CREB-binding protein (CBP)/p300 to exert their functions. Similarly, AP-1 also requires $\mathrm{CBP} / \mathrm{p} 300$ to regulate the target gene expression. Thus, PPARs and AP-1 scramble competitively for limiting pool of overlapping sets of coactivator in cells ${ }^{[48]}$. Li et al. have demonstrated that transrepression by PPAR- $\gamma$ is achieved by targeting CBP through direct interaction with its N-terminal domain and via SRC-1-like bridge factors ${ }^{[49]}$. This is the fourth mechanism of transrepression (Figure 2d). Lee and the colleagues proposed a ligand-dependent transcriptional pathway in which PPAR- $\beta / \delta$ controls an inflammatory switch through its association and disassociation with BCL-6 ${ }^{[50]}$. PPAR- $\beta / \delta$-BCL- 6 complex possesses pro-inflammatory effect when PPAR- $\beta / \delta$ is unliganded. Once PPAR- $\beta / \delta$ activated by the ligand, BCL- 6 is released from the complex and then suppresses the production of cytokines and chemokines (Figure 2e). Pascual et al proposed another corepressor-dependent model that PPAR- $\gamma$ mediates transrepression of a subset of inflammatory response genes in macrophages by preventing the signal-dependent clearance of corepressor complexes on inflammatory promoters downstream of LPS signaling ${ }^{[51]}$. Based on its anti-inflammatory activities as described above, PPARs are expected to be therapeutic targets for treatment of different inflammatory skin diseases ${ }^{[52]}$.

\begin{tabular}{cl}
\hline Up-regulation & \multicolumn{1}{c}{ Down-regulation } \\
\hline $\mathbb{L}-4, \mathrm{IL}-5, \mathrm{sIL}-1 \mathrm{ra}$ & $\mathrm{IL}-1 \beta, \mathrm{IL}-6, \mathrm{IL}-12, \mathrm{IL}-23, \mathrm{IL}-27$ \\
& $\mathrm{CCL} 2$ (MCP-1), CCL4 (MIP), CXCL8 (IL-8) \\
& IFN- $\gamma, \mathrm{TNF}-\alpha$ \\
& $\mathrm{ICAM}-1, \mathrm{VCAM}-1$ \\
& $\mathrm{ET}-1$ \\
& $\mathrm{COX}-2$, iNOS \\
\end{tabular}

Table 2. Influence of PPAR activation on inflammatory molecule expression 

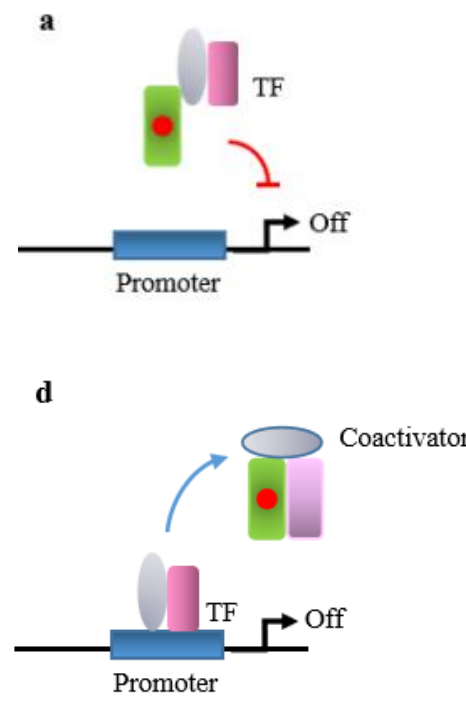

b
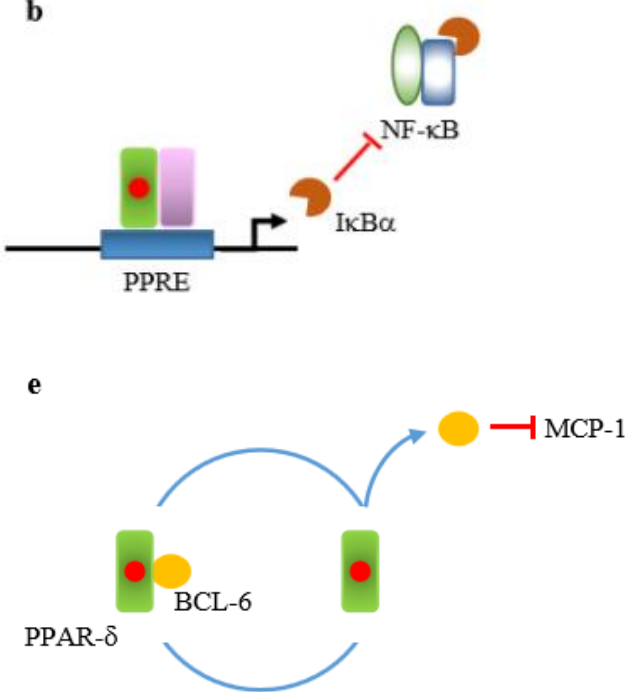

$\mathbf{c}$

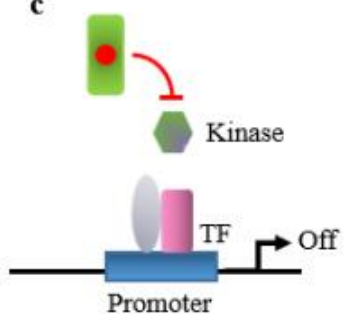

Figure 2; Mechanisms of liganded PPAR-mediated transsppression. a) Direct interaction with transcription factor (TF), b) Induction of $\mathrm{I} \kappa \mathrm{B} \alpha, \mathrm{c})$ Kinase inhibition, d) Competitive scramble for coactivator, e) Association and disassociation with BCL-6.

\section{Skin barrier disruption in atopic dermatitis}

Atopic dermatitis (AD) is a chronic and relapsing disease. Its increasing prevalence to be estimated up to $20 \%$ in children and 10\% in adults represents a major public-health problem. $\mathrm{AD}$ is characterized skin barrier dysfunction and immune dysregulation. From the aspect of skin barrier dysfunction, a typical characteristic of $\mathrm{AD}$ is xerosis which affects lesional and non-lesional skin areas, due to increased transepidermal water loss. Previous studies have proposed two major causes of increased transepidermal water loss: (i) decreased ceramide content in strarum corneum ${ }^{[53]}$, (ii) filaggrin gene mutation ${ }^{[54]}$. This skin barrier disturbance exacerbates $\mathrm{AD}$, due to facile penetration of molecules such as antigens ${ }^{[5]}$. Thus, the application of emollients such as urea and heparinoid is one of the basic treatments to support skin barrier function and allow hydration of the skin as conservative treatments ${ }^{[6]}$. On the other hand, it is supposed that hyperproliferation and hypodifferentiation of keratinocyte are the factors for skin barrier dysfunction in $\mathrm{AD}$, other than gene mutation ${ }^{[55,56]}$. A previous report demonstrated that PPAR $\beta / \delta$ plays crucial roles in keratinocyte proliferation, maintenance of cutaneous barrier homeostasis and regulation of inflammation in PPAR $\beta / \delta$ deficient mice ${ }^{[57]}$. To establish a mature skin barrier function mechanically, sequential and orchestrated cross-linking of filaggrin, involucrin, loricrin and ceramides by transglutaminase 1 along with keratinocyte differentiation is required. Han- ley et al. reported that clofibrate, a PPAR $\alpha$ agonist, decelerates keratinocyte proliferation and accelerate differentiation with enhancement of mRNA expression of involucrin and transglutaminase $1^{[58]}$. Other studies demonstrated that caffeic acid induces keratinocyte differentiation via PPAR- $\alpha$ activation $^{[59]}$, and that GW0742, a PPAR- $\beta / \delta$ selective activator, induces keratinocyte differentiation and inhibits proliferation ${ }^{[60]}$. Addition to the regulation of keratinocyte differentiation, intracellular lipid accumulation and lamellar body secretion are crucial for the construction of intercellular lipid alignment to contribute skin barrier function. Schmuth et al. provided crucial evidence on relation between PPAR- $\beta / \delta$ activation and skin barrier homeostasis: i) PPAR $-\beta / \delta$ activator, GW1514, stimulates the recovery of acute and chronic skin perturbation in hairless mice, ii) GW1514 stimulates an increase in the expression of the differentiation markers, loricrin and filaggrin, iii) GW1514 increases accumulation of triglyceride ${ }^{[61]}$. A consecutive study from the same group demonstrated that application of activators of PPAR $\alpha$ (WY14643), PPAR $\beta / \delta$ (GW1514) and PPAR $\gamma$ (ciglitazone) to hairless mice enhances synthesis of cholesterol, fatty acid and ceramides, and consequently that the activators accelerate the recovery from acute disruption of skin barrier function ${ }^{[62]}$. These results suggest that PPAR activators are expected to improve cutaneous barrier homeostasis by control of keratinocyte differentiation. Further, other studies showed that activation of PPAR- $\alpha$ by WY14643 improves skin barrier 
with normalization of the molar ratio of the main skin barrier lipids to $1: 1: 1$ (free fatty acids:ceramides:cholesterol) and upregulation of filaggrin expression $^{[63]}$, and that oat lipid extract, which demonstrates robust dual agonism for PPAR- $\alpha$ and PPAR- $\beta / \delta$, enhances keratinocyte differentiation and ceramide synthesis $^{[64]}$. These results suggest that PPAR activators are expected to be alternative treatments to support skin barrier function.

\section{Attenuation of innate immunity in $\mathrm{AD}$}

On the other hand, immune dysregulation in both innate and acquired immunity is another important aspect in AD. Especially, cytokines in innate and acquired immunity contribute to establish the pathology of $\mathrm{AD}^{[65]}$. The innate immunity presents in epidermis as the front line defense against infection. Antimicrobial peptides (AMPs) such as cathelidin (LL37) and $\beta$-defensins, directly kill a broad spectrum of microbes, including Gram-positive and Gram-negative bacteria as well as fungi and certain viruses, are secreted from keratinocyte and activated to respond immediately after microbial invasion. Although it is supposed that AD patients have a higher prevalence of infection with bacteria, fungi, and viruses due to skin barrier disruption, the defects of innate immune system are demonstrated previously ${ }^{[7]}$. Ong et al. reported that the expression of LL37 and human $\beta$-defensin 2 (HBD-2) was suppressed in AD patients ${ }^{[8]}$. As the expression of AMPs arises during keratinocyte differentiation, the disturbance of keratinocyte differentiation is a considerable reason why suppression of LL37 and HBD-2 occurs in AD patients. Because PPARs activators induce keratinocyte differentiation ${ }^{[59,61,66,67]}$, PPAR activation may improve AMPs production in AD. Furthermore, a previous study reported that apoptosis signal-regulating kinase-1 (ASK1), an intracellular regulator of keratinocyte differentiation, enhances the expression of LL37 and HBD2 via p38 cascade ${ }^{[68]}$. Since PPAR/p38 pathway is one of the signal cascade to exert the functions, similar to ASK $1^{[69,70]}$, PPAR activation is expected to induce AMP expression via p38. In fact, Dai et al. showed that PPAR $\gamma$ regulates the $1 \alpha$, 25-dihydroxyvitamin $\mathrm{D}_{3}$-induced production of HBD-3 and LL37, whose gene is a direct target of the vitamin D receptor, in keratinocytes through the regulation of AP-1 and p38 activity $^{[71-74]}$.

\section{Dysregulation of acquired im- munity in AD}

Regarding dysregulation of acquired immunity, AD is originally considered as a Th2-mediated disease because of the systemic elevation of Th2 cytokines with increased IgE levels and eosinophilia in the acute phase ${ }^{[6,8]}$. Once keratinocytes, locating the outmost of the body, are activated by diverse stimuli including chemicals, allergens, microbes and scratching, they release thymic stromal lymphopoetin (TSLP), IL-25 and IL-33. TSLP is produced from keratinocytes by tape stripping-induced skin barrier disruption and by Staphylococcus aureus, as well as antigen-activated mast cells (MC) ${ }^{[75-77]}$. Additionally, the high expression of TSLP in keratinocytes from patients with AD implies involvement of TSLP in $\mathrm{AD}^{[78]}$. Previous studies demonstrated that IL-25 expression is found in Th2 cells, allergen-activated MCs, eosinophils, basophils, dendritic cells (DC) and human skin of AD patients ${ }^{[79-82]}$. IL-33 is expressed by a wide variety of cell types, including residing and infiltrating cells in skin ${ }^{[83]}$. These cytokines share the properties which induce IL-4, IL-5 and IL-13 production to lead skewing and augmenting $\mathrm{Th} 2$ response in $\mathrm{AD}^{[79,81]}$. Interestingly, a previous study demonstrated that TNF- $\alpha$-induced HBD-2 production from HaCaT cells is significantly decreased in the presence of IL- 4 or IL-13 ${ }^{[7]}$, suggesting that IL-4 and IL-13 affect the innate immune system in $\mathrm{AD}$. In addition, IL-25 is suggested to participate in barrier dysfunction in AD because IL-25 reduces filaggrin expression in keratinocyte ${ }^{[81]}$. Additionally, IL-33 stimulates MCs to produce IL-5, IL-6, IL-10, IL-13, TNF- $\alpha$ and GM-CSF ${ }^{[84]}$. Of them, TNF- $\alpha$ stimulates keratinocytes to produce $\operatorname{TSLP}^{[65]}$. Following the production of TSLP, IL-25 and IL-33 to target Th2 cells, Th2-cytokines including IL-4, IL-5 and IL-13 are released. Their functions in acquire immune response are; i) IL-4 induces immunoglobulin class switch form IgM to $\mathrm{IgE}$, and upregulates $\mathrm{IgE}$ receptors on monocytes, as well as promotion of Th2 skewing, ii) IL-5 induces the production of IL-25 from eosinophils and stimulates maturation and also activation of eosinophis, iii) the effects of IL-13 are similar to those of IL-4. The patients with AD are divided into extrinsic $\mathrm{AD}(\mathrm{EAD})$ and intrinsic $\mathrm{AD}$ (IAD). In EAD, increased total serum IgE and a higher 
expression of $\mathrm{IgE}$ receptors on monocytes are found, compared with IAD. On the other hand, higher expression of IL-5 and IL-13 are detected in EAD than IAD. However, the expression of Th2 cytokines including IL-4, IL-5 and IL-13 in skin lesions of both group is elevated, compared with normal control skin ${ }^{[85-87]}$. IL-31, belonging to an IL-6 family in terms of its structure and receptor complex, is expressed by Th2 cells ${ }^{[88]}$. Raap et al. reported a correlation between serum levels of IL-31 and the severity of $\mathrm{AD}^{[89]}$. A role of IL-31 is to induce the release of pro-inflammatory cytokines including IL-1 $\beta$ and IL-6, and AD-related chemokines including CXCL1, CXCL8, CCL2 and CCL18 from eosinophils whose infiltration in skin lesions is a predominant pathological feature of $\mathrm{AD}^{[90]}$. In addition, IL-31 is focused as a major pruritogen associated with $\mathrm{AD}^{[91]}$. Because scratching behavior due to pruritus is an exacerbation factor to influence the quality of life, the control of pruritus is important. In $\mathrm{NC} / \mathrm{Nga}$ mice developing spontaneously AD-like skin lesions, long-lasting scratching behavior and IL-31 expression is enhanced, while both of them is unchanged in TNCB-induced contact dermatitis and this scratching behavior is ameliorated by administration of anti-IL-31 antibody ${ }^{[92,93]}$. These suggest the importance of Th2 cytokines in the pathogenesis of acute phase in $\mathrm{AD}$. It is well known that cytokine profile in $\mathrm{AD}$ shifts from Th2 dominant in acute phase to Th1 dominant in chronic phase, as it is called "Th1/Th2 paradigm"[94-97]. Indeed, increased levels of IL-12 and IFN- $\gamma$, which represent Th1 cytokines, are detected in chronic AD lesions, compared with normal skin ${ }^{[8]}$. Previously, Aral et al. demonstrated that serum level of IL-18 is found significantly higher in $\mathrm{AD}$ patients than in controls and that a statistically significant relationship between the severity of AD, and serum levels of IL-18 and IL-12/p40 is determined, suggesting the involvement of IL-18 in $\mathrm{AD}^{[9]}$. IL-18, derived from dendritic cells, induces Th1 cells to produce Th1 cytokines ${ }^{[66,98]}$. Moreover, other studies suggest the roles of IL-18 in the pathogenesis of $\mathrm{AD}^{\text {[99-101] }}$. However, because the conflict results in relationship between IL-18 and atopic dermatitis-like inflammation $^{[102]}$, the role of IL-18 in atopic dermatitis should be further addressed. IL-21, a member of the type I cytokine family, is produced by lymphoid cells such as activated $\mathrm{CD}^{+} \mathrm{T}$ cells and exerts its pleiotropic func- tion by binding to IL-21 receptor (IL-21R). Upregulation of IL-21 and IL-21R in skin lesions from AD patients and elevated levels of IL-21 in serum form AD patients are reported ${ }^{[103,104]}$. In mice, skin barrier disruption, a surrogate for scratching, enhances the expression of IL-21 and IL-21R, as well as IL-6 ${ }^{[103]}$. Further, IL-21 enhances CCR7 expression, migration to local lymphnode and antigen presentation of $\mathrm{DCs}^{[105]}$. In addition to Th1/Th2 paradigm, Th17 cells and Th22 cells emerged as new participants in the pathogenesis of AD. The cell number of intracellular IL-17 positive circulating lymphocyte, mRNA expression of IL-17 in peripheral blood mononuclear cells and IL-17 concentration in serum are upregulated in the patient with $\mathrm{AD}$, correlated with the severity of $\mathrm{AD}^{[106,107]}$. IL-17 directly enhances $\mathrm{IgE}$ production, but not $\operatorname{IgG}, \operatorname{IgM}$ or $\operatorname{IgA}$, in human by triggering rapid degradation of $\mathrm{I} \kappa \mathrm{Ba}$ and subsequent translocation of NF- $\mathrm{B}$ into the B-cell nucleus ${ }^{[108]}$. Th22 cells were identified as CD4+ T cell producing IL-22 and lacking production of IL-17 and are distinct from Th1, Th2 and Th17 cells ${ }^{[109-111]}$. IL-22 induces the expression of S100A7, S100A8 and S100A9, a group of proinflammatory molecules, in human keratinocyte, as well as matrix metalloproteinase 3 and CXCL5. In addition, IL-22 induces keratinocyte migration in an in vitro injury model and downregulates the expression of keratinocyte differentiation markers including involucrin, loricrin, heat shock protein 27 , calmodulin-related protein and heme oxygenase 1. Further, in reconstituted human epidermis, IL-22 induces strongly hyperplasia ${ }^{[112]}$. The number of Th2 and Th22 cells are significantly elevated in AD, whereas psoriatic skin has significantly increased frequency of Th1 and Th17 cell. The levels of IL-22 is upregulated in $\mathrm{AD}$ lesions, associated with the severity of AD symptoms ${ }^{[113]}$. These findings suggested that IL-22 affects to maintenance of inflammation and epidermal hyperplasia in AD. Taken together, AD is a Th2/Th22 skewed disease, with additional contributions from Th1 cytokines occurring in the chronic stage. Overlooking this complicated pathogenesis of AD, a simple question, whether this complicated cytokine network in AD can be regulated by the activation of PPARs, is raised. To simplify the cytokine network, the intracellular signaling pathway activated by these cytokines are focused. As shown in Table 3, JAK/STAT or NF- $\mathrm{BB}$ is involved in all 
signaling pathways activated by cytokines in AD. PPAR $-\alpha$ interacts with NF- $\kappa$ B and AP-1 and PPAR- $\gamma$ interacts with STAT, NF- $\mathrm{B}, \mathrm{AP}-1$ and NF-AT ${ }^{[42]}$. Consequently, the gene expression in the down-stream involving by these transcription factors is reduced. Likewise, we examined the effects of PPAR- $\delta$ activation by GW501516 on IL-6 and IL-8 production from HaCaT cells, an immortalized keratinocyte derived from human epidermis. Expectedly, LPS-induced IL-6 production and TNF- $\alpha$-induced IL- 8 production are reduced with GW501516 treatment (Figure 3). Following the results from in vitro experiments, in vivo experiments in animal models, including gene-modified animals and classical (traditional) animal, are required to elucidate the effect of PPAR activation on AD. Actually, Kim et al. demonstrated that ursolic acid, a potential PPAR- $\gamma$ agonist, suppresses ovalbumin-induced airway inflammation with the downregulation of IL-5, IL-13 and IL-17 ${ }^{[114]}$. In dermatological field, two groups reported the effect of PPAR activators on oxazolone-induced contact dermatitis in mice, as an atopic dermatitis model ${ }^{[115,116]}$. NC/Nga mouse is known as an animal model for $\mathrm{AD}$. NC/Nga mice are originated from Japanese fancy mice (Nishi-
ki-Nezumi) and were established as a inbred strain in 1955. The most important characteristic in NC/Nga mice is that spontaneous AD-like dermatitis appears in the mice raised under ambient laboratory conditions, while no skin lesion is detected clinically in the mice raised under specific pathogen-free condition. Additionally, previous studies have revealed the other features, including the skin barrier dysfunction with the reduction of ceramide contents, IgE hyperproduction, cytokine profiles and long-lasting scratching behavior, corresponding to human $\mathrm{AD}^{[117-120,92]}$. Therefore $\mathrm{NC} / \mathrm{Nga}$ mice are widely used for evaluation of the therapeutic effect for AD. Chiba et al. showed that topical application (transdermal) of PPAR- $\alpha$ suppresses atopic dermatitis in NC/Nga mice ${ }^{[121]}$. Recently, a study showed that tannic acid ameliorates clinical severity in house dust mite extract-induced AD-like dermatitis in $\mathrm{NC} / \mathrm{Nga}$ mice, with pathologically inhibition of hyperkeratosis, parakeratosis, acanthosis and infiltration of inflammatory cell ${ }^{[122]}$. To follow the antecedent studies on the effect of PPAR activation on skin barrier dysfunction in $A D$, further studies should be performed to elucidate the effects of PPAR activation on immune-modulation in AD.

\begin{tabular}{lc}
\hline Cytokine & Kinase/Transcription factor \\
\hline IL-4 & JAK3/STAT6 \\
IL-5 & RAS/MAPK, JAK/STAT, PI3K \\
IL-13 & JAK3/STAT6 \\
IL-22 & NF-KB \\
IL-25 & JAK1/STAT3, Tyk2/STAT3, MAPK/STAT3 \\
IL-31 & JAK1/STAT3, JAK1/STAT5, JAK2/STAT3, JAK2/STAT5, PI3K/AKT \\
IL-33 & NF-KB \\
TSLP & JAK2/STAT3, JAK2/STAT5 \\
\hline
\end{tabular}

Table 3. Kinases/Tanscription factors in signaling pathways of AD cytokines
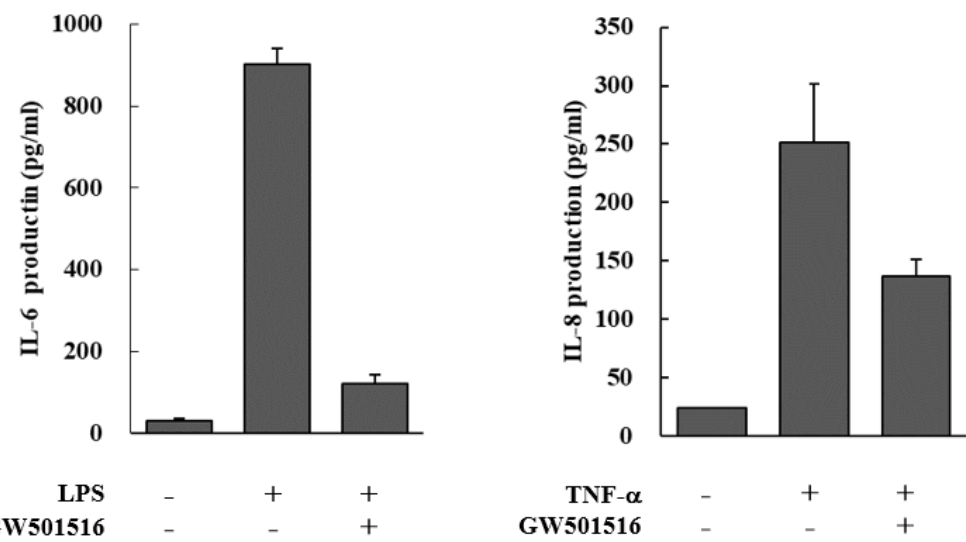

Figure 3; Suppression of inflammatory cytokine production by PPAR- $\delta$ agonist (GW501516). Treatment with GW501516 suppresses LPS-induced IL-6 production and TNF- $\alpha$-induced IL-8 production from HaCaT cells. 


\section{Conclusion}

Depending to pleiotropic function of PPARs, therapeutic applications of PPAR activators have been expected. Actually, some of agonists for PPAR- $\gamma$ have already used in diabetes therapy. It is easily hypothesized that PPAR activators, which possess suppressive effects on transcription factors, may improve skin inflammation, including $\mathrm{AD}$. Indeed, numerous numbers of in vitro experiments have been performed and provided useful information. Regarding to $\mathrm{AD}$, although previous studies suggest that PPAR activation may be useful for improvement of skin barrier dysfunction and that PPAR activation suppresses the inflammatory molecules via inhibition of transcriptional pathways, the usefulness of PPAR activation for immune dysregulation is still unclear, due to its complicated cytokine network. However, some in vivo studies put the beacons to resolve the underlying issues. Thus, PPAR activation is expected to be one of the immune-modulating therapy for $\mathrm{AD}$.

\section{References}

1. Issemann I, Green S. Activation of a member of the steroid receptor superfamily by peroxisome proliferator. Nature 1990; 347: 645-649 doi: 10.1038/ $347645 \mathrm{a} 0$.

2. Sher T, Hua-Fang Y, McBride O. et al. cDNA cloning, chromosomal mapping, and functional characterization of the human peroxisome proliferator activated receptor. Biochemistry 1993; 32:5598-5604 doi:10.1021/bi00072a015.

3. Lamichane S, Lamichane BD, Kwon SM. Pivotal roles of peroxisome proliferator-activated receptors (PPARs) and their signal cascade for cellular and whole-body energy homeostasis. Intl J Mol Sci 2018; 19(4): 949. doi:10.3390/ijms19040949.

4. Westergaard M, Henningsen J, Svendsen ML. et al.

15. monoclonal antibody (Mepolizumab) for the treatment of atopic dermatitis. Allergy 2005; 60(5):693696. doi: 10.1111/j.1398-9995.2005.00791.x

16. Braissant O, Foufelle F, Scotto G, et al. Differential expression of peroxisome proliferator-activated receptor (PPARs): tissue distribution of PPAR-alpha, -beta and -gamma in the adult rat. Endocrinology 1996; 137 (1): 354-366. doi: 10.1210/endo.137.1. 8536636.

17. Palmer CN, Hsu MH, Griffin KJ, et al. Peroxisome proliferator-activated receptor alpha expression in human liver. Mol Pharmacol 1998; 53 (1): 14-22. doi: $10.1124 / \mathrm{mol} .53 .1 .14$.

18. Auboeuf D, Rieusset J, Fajas L, et al. Tissue distribution and quantification of the expression of mRNAs of peroxisome proliferator-activated receptors and live $\mathrm{X}$ receptor-alpha in human: no al-
Modulation of keratinocyte gene expression and differentiation by PPAR-selective ligands and tetradecylthioacetic acid. J. Invest. Dermatol. 2001; 116(5): 702-712 doi: 10.1046/j.1523-1747.2001. 01329.x.

5. Proksch E, Folster-Holst R, Jensen JM, et al. Skin barrier function, epidermal proliferation and differentiation in eczema. J Dermatol Sci 2006; 43 (3):159-169. doi: 10.1016/j.jdermsci.2006.06.003

6. Bieber T. Atopic dermatitis. Ann Dermatol 2010; 22 (2):125-137. doi: 10.5021/ad.2010.22.2.125.

7. McGirt LY, Beck LA. Innate immune defects in atopic dermatitis. J Allergy Clin Immunol 2006; 118 (1): 202-208. doi: 10.1016/j.jaci.2006.04.033

8. Ong PY, Leung DY. Immune dysregulation in atopic dermatitis. Curr Allergy and Asthma Reports 2006; 6 (5): 384-389. doi: 10.1007/s11882996-0008 -5.

9. Aral M, Arican O, Gul M, et al. The Relationship between serum levels of total IgE, IL-18, IL-12, IFN- $\gamma$ and disease severity in children with atopic dermatitis. Mediators Inflamm. 2006; 2006 (4):1-4. doi: 10.1155/MI/2006/73098.

10. Maa L, Xueb HB, Guan XH, et al. Possible role of Th17 cells and IL-17 in the pathogenesis of atopic dermatitis in northern China. J Dermatol Sci 2012; 68 (1): 66-68 doi: 10.1016/j.jdermsci.2012.07.009

11. Nakahara $\mathrm{T}$, Morimoto $\mathrm{H}$, Murakami $\mathrm{N}$, et al. Mechanistic insights into topical tacrolimus for the treatment of atopic dermatitis. Pediatr Allery Immunol 2018; 29 (3): 233-238. doi: 10.1111/pai. 12842.

12. Montes-Torres A, Llamas-Velasco M, Pérez-Plaza A, et al. Biological treatments in atopic dermatitis. J Clin Med 2015; 4 (4): 593-13. doi; 10.3390/jcm 4040593.

13. Beck LA, Thaçi D, Hamilton JD, et al. Dupilumab treatment in adults with moderate-to-severe atopic dermatitis. N Engl J Med 2014; 371(2):130-139. doi: 10.1056/NEJMoa1314768.

14. Oldhoff JM. Anti-IL-5 recombinant humanized

teration in adipose tissue of obese and NIDDM patients. Diabetes 1997; 46 (8): 1319-1327. doi: 10. 2337/diabetes.46.8.1319

19. Escher P, Braissant O, Basu-Modak S, et al. Rat PPARs: quantitative analysis in adult rat tissues and regulation in fasting and refeeding. Endocrinology 2001; 142 (10): 4195-4202. doi: 10.1210/en.142.10. 4195

20. Michalic L, Desvergbe B, Basa-Modak S, et al. Nuclear hormone receptor and mouse skin homeostasis: implication of PPAR beta. Hormone Res 2000; 54 (5-6): 263-26 .doi: 10.1159/000053269

21. Rivier M, Safonova I, Lebrun P, et al. Differential expression of peroxisome proliferator-activated receptor subtypes during the differentiation of human keratinocytes, J. Invest. Dermatol. 1998; 111 (6): 1116-1121. doi: 10.1046/j.1523-1747.1998.00 
439.x.

22. Yang LP, Keating GM. Fenofibric acid: in combination therapy in the treatment of mixed dyslipidemia". Am J Cardiovasc Drugs 2009; 9 (6): 401-409 doi: 10.2165/11203920-000000000-00000.

23. Steiner G. How can we improve the management of vascular risk in type 2 diabetes: insights from FIELD. Cardiovasc Drugs Ther 2009; 23 (5): 403-8 doi: 10.1007/s10557-009-6190-7.

24. Berger J, Moller DE. The mechanisms of action of PPARs. Annu Rev Med 2002; 53: 409-435.

25. Miyata KS, McCaw SE, Marcus SL, et al. The peroxisome proliferator-activated receptor interact with the retinoid X receptor. Gene 1994; 148 (2): 327-330. doi: 10.1016/0378-1119(94) 90707-2.

26. Krey G, Keller H, Mahfoudi A, et al. Xenopus peroxisome proliferator-activated receptors: genomic organization, response element recognition, heterodimer formation with retinoid $\mathrm{X}$ receptor and activation by fatty acid. J Steroid Biochem Mol Biol 1993; 47 (1): 65-73 doi: 10.1016/0960-0760(93) 90058-5.

27. IJpenberg AI, Jeannin E, Wahli W, et al. Polarity and specific sequence requirement of peroxisome proliferator-activated receptor (PPAR)/retinoid X receptor heterodimer binding to DNA. A functional analysis of the malic enzyme gene PPAR response element. J Biol Chem 1997; 272 (32):20108-20117 doi: 10.1074/jbc.272.32.20108.

28. Ricote M, Glass CK. PPARs and molecular mechanism of transcription. Biochim Biophys Acta 2007; 1771 (8): 926-936. doi: 10.1016/j.bbalip.2007.02. 013.

29. Ahmed AU. An overview of inflammation: mechanism and consequences. Front Biol 2011; 6 (4):274-281. doi: 10.1007/s11515-011-1123-9.

30. Akira S, Uematsu S, Takeuchi O. Pathogen recognition and innate immunity. Cell 2006; 124 (4): 783-781. doi: 10.1016/j.cell.2006.02.015.

31. Hou X, Pei F. Estradiol inhibits cytokine-induced expression of VCAM-1 and ICAM-1 in cultured human endothelial cells via AMPK/PPAR $\alpha$ activation. Cell Biochem Biophys 2015; 72 (3): 709-717 doi: 10.1007/s12013-015-0522-y.

32. Hammond ME, Lapointe GR, Feucht PH. IL-8 induces neutrophil chemotaxis predominantly via type I IL-8 receptors. J Immunol 1995; 155 (3): 1428-1433.

33. Devchand PR, Keller H, Peters JM, et al. The PPAR $\alpha$-leukotriene B4 pathway to inflammation control, Nature 1996; 384: 39-43 doi: 10.1038/ $384039 \mathrm{a} 0$.

34. Jiang C, Ting AT, Sees B. PPAR- $\gamma$ agonists inhibit production of monocyte inflammatory cytokines. Nature 1998; 391: 83-86. doi: 10.1038/34184.

35. Staels B, Koenig W, Habib A, R. et al. Activation of human aortic smooth-muscle cells is inhibited by PPAR alpha but not by PPAR gamma activators, Nature 1998; 393:790-793 doi: 10.1038/31701
36. Marx N, Sukhova GK, Collins T, et al. PPAR alpha activators inhibit cytokine-induced vascular cell adhesion molecule-1 expression in human endothelial cells, Circulation 1999; 99 (24): 3125-3131.

37. Welch JS, Ricote M, Akiyama TE, et al. PPAR $\gamma$ and PPAR $\delta$ negatively regulate specific subsets of lipopolysaccharide and IFN $\gamma$ target genes in macrophages, Proc Natl Acad Sci USA 2003; 100(11):6712-6717 doi: 10.1073/pnas. 1031789100

38. Ding G, Cheng L, Qin Q, et al. PPAR delta modulates lipopolysaccharide-induced TNFalpha inflammation signaling in cultured cardiomyocytes, J Mol Cell Cardiol 2006; 40 (6): 821-828 doi: 10.1016/j.yjmcc.2006.03.422.

39. Natarajan C, Bright JJ. Peroxisome proliferator-activated receptor-gamma agonists inhibit experimental allergic encephalomyelitis by blocking IL-12 production, IL-12 signaling and Th1 differentiation. Genes and Immunity 2002; 3 (2): 59-70. doi: $10.1038 / \mathrm{sj} /$ gene/6363832.

40. Gervois P, Mansouri RM. PPAR $\alpha$ as a therapeutic target in inflammation-associated diseases. Expert Opin Ther Targets 2012; 16(11):1113-1125. doi: 10.1517/14728222.2012.715633.

41. Kuribayashi S, Xu X, Ishii S, et al. A novel thiazolidinediones MCC-555 down-regulates tumor necrosis factor- $\alpha$-induced expression of vascular adhesion molecule-a in vascular endothelial cells. Atherosclerosis 2005; 182 (1): 71-77. doi: 10.1016/j.atherosclerosis.2005.01.043.

42. Tyrone E, James PG, Zineh WI. Modulatory effect of fenofibrate on endothelia production of neutrophil chemokines IL-8 and ENA-78. Cardiovasc Drugs Ther 2012; 26 (2): 95-99. doi: 10.1007/s105 57 -011-6368-7.

43. Kostadinova R, Wahli W, Michalik L. PPARs in diseases: Control mechanisms of inflammation. Curr Med Chem 2005; 12 (25): 2995-3009. doi: $10.2174 / 092986705774462905$.

44. Delerive P, De Bosscher K, Besnard S, et al. Peroxisome proliferator-activated receptor $\alpha$ negatively regulates the vascular inflammatory gene response by negative cross-talk with transcription factors NF-kappaB and AP-1. J. Biol. Chem. 1999; 274 (45): 32048-32054. doi: 10.1074/jbc.274.45. 32048

45. Delerive $\mathrm{P}$, Gervois P, Fruchart C, et al. Induction of IkappaB alpha expression as a mechanism contributing to the anti-inflammatory activities of peroxisome proliferator-activated receptor alpha activators, J. Biol. Chem. 2000; 275 (47): 36703 36707. doi: 10.1074/jbc.M004045200

46. Desreumaux P, Dubuquoy L, Nutten S, et al. Attenuation of colon inflammation through activators of the retinoid $\mathrm{X}$ receptor $(\mathrm{RXR}) /$ peroxisome proliferator-activated aeceptor $\mathrm{g}$ (PPAR $\gamma$ ) heterodimer: A basis for new therapeutic strategies. J Exp Med 2001; 193 (7): 827-838. doi: 10.1084/jem.193.7. 827. 
47. Kim JS, Lee YH, Chang YU, et al. PPAR $\gamma$ regulates inflammatory reaction by inhibiting the MAPK/NF- $\kappa \mathrm{B}$ pathway in $\mathrm{C} 2 \mathrm{C} 12$ skeletal muscle cells. J Physiol Biochem 2017; 73 (1): 49-57 doi: 10.1007/s13105-016-0523-3.

48. Shi L, Lin Q, Li X, et al. Alliin, a garlic organosulfur compound, ameliorates gut inflammation through MAPK-NF- $\mathrm{B} / \mathrm{AP}-1 / \mathrm{STAT}-1$ inactivation and PPAR- $\gamma$ activation. Mol Nutr Food Res 2017; 61 (9):1601013. doi: 10.1002/mnfr.201601013.

49. Kamei Y, Xu L, Heinzel T, et al. A CBP integrator complex mediates transcriptional activation and AP-1 inhibition by nuclear receptor. Cell 1996; 85 (3):403-414. doi: 10.1016/S0092-8674(00)81118-6

50. Li M, Pascual G, Glass CK. Peroxisome proliferator-activated receptor $\gamma$-dependent repression of the inducible nitric oxide synthase gene. Mol Cell Biol 2000; 20 (13): 4699-4707. doi: 10.1128/MCB.20.13. 4699-4707.2000.

51. Lee $\mathrm{CH}$, Chawla A. Urbiztondo $\mathrm{N}$, et al. Transcriptional repression of atherogenic inflammation: modulation by PPAR $\delta$ Science 2003; 302 (5644): 453-457. doi: 10.1126/science.1087344.

52. Pascual G, Fong AL, Ogawa S, et al. A SUMOylation-dependent pathway mediates transrepression of inflammatory response genes by PPAR- $\gamma$. Nature 2005; 437:759-763 doi: 10.1038/nature03988.

53. Sertznig P, Reichrath J. Peroxisome proliferator-activated receptors (PPARs) in dermatology. Dermato-Endocrinol 2011; 3 (3): 130-135 doi: 10.4161/derm. 15025 .

54. Imokawa G, Abe A, Jin K et al. Decreased level of ceramides in stratum corneum of atopic dermatitis: an etiologic factor in atopic dry skin? J Invest Dermatol 1991; 96 (4): 526-526 doi: 10.1111/15231747. ep12470233.

55. Osawa R, Konno S, Akiyama M, et al. Japanese-specific filaggrin gene mutations in Japanese patients suffering from atopic eczema and asthma. J Invest Dermatol 2010; 130 (12): 2834-2836. doi:

64. matol 2006; 126 (2): 386-392. doi: 10.1038/sj.jid. 5700046.

65. Wallmeyera L, Lehnena D, Eger N, et al. Stimulation of PPAR $\alpha$ normalizes the skin lipid ratio and improves the skin barrier of normal and filaggrin deficient reconstructed skin. J Dermatol Sci 2015; 80(2):102-110. doi: 10.1016/j.jdermsci.2015.09.012

66. Chon SH, Tannahill R, Yao X, et al. Keratinocyte differentiation and upregulation of ceramide synthesis induced by an oat lipid extract via the activation of PPAR pathways. Exp Dermatol 2015; 24 (4): 290-295. doi: 10.1111/exd.12658.

67. Carmi-Levy I, Homey B, Soumelis V. A modular view of cytokine networks in atopic dermatitis. Clinic Rev Allerg Immunol 2011; 41 (3): 245-253. doi: 10.1007/s12016-010-8239-6.

68. Yan Y, Furumura M, Numata S, et al. Various peroxisome proliferator-activated receptor (PPAR)- $\gamma$ agonists differently induce differentiation of cul-
10. 1038/jid.2010.218.

56. Glatzer F, Gschwandtner M, Ehling S, et al. Histamine induces proliferation in keratinocytes from patients with atopic dermatitis through the histamine 4 receptor. J Allergy Clin Immunol 2013; 132 (6): 1358-1367 doi: 10.1016/j.jaci.2013.06.023.

57. Mantel A, Carpenter-Mendini AB, Buskirk AB, et al. Aldo-Keto reductase $1 \mathrm{C} 3$ is expressed in dfferentiated human epidermis, affects keratinocyte differentiation, and is upregulated in atopic dermatitis, J Invest Dermatol 2012; 132(4):1103-1110 doi: 10.1038/jid.2011.412

58. Man MQ, Barish GD, Schmuth M, et al. Deficiency of $\operatorname{PPAR} \beta / \delta$ in the epidermis results in defective cutaneous permeability barrier homeostasis and increased inflammation. J Invest Dermatol 2008; 128 (2): 370-377. doi: 10.1038/sj.jid.5701026.

59. Hanley K, Jiang Y, He SS, et al. Keratinocyte differentiation is stimulated by activators of the nuclear hormone receptor PPAR $\alpha$. J Invest Dermatol 1998; 110 (4): 368-375. doi: 10.1046/j.1523-1747. 1998.00139.x.

60. Kim B, Kim JE, Kim HS. Caffeic acid induces keratinocyte differentiation by activation of PPAR- $\alpha$ J Pharm Pharmacol 2014; 66 (1): 84-92. doi: 10.1111/jphp.12159.

61. Kim DJ, Bility MT, Billin AN, et al. PPAR $\beta / \delta$ selectively induces differentiation and inhibits cell proliferation. Cell Death Differ 2006; 13 (1): 53-60 doi: 10.1038/sj.cdd.4401713.

62. Schmuth M, Haqq CM, Cairns WJ, et al. Peroxisome proliferator-activated receptor (PPAR) $-\beta / \delta$ stimulates differentiation and lipid accumulation in keratinocytes. J Invest Dermatol 2004; 122 (4): 971-983. doi: 10.1111/j.0022-202X.2004.22412.x.

63. Man MQ, Choi EH, Schmuth M, et al. Basis for improved permeability barrier homeostasis induced by PPAR and LXR activators: Liposensors stimulate lipid synthesis, lamellar body secretion, and post-secretory lipid processing. J Invest Der tured human keratinocytes. Exp Dermatol 2015; 24(1):62-65 doi: 10.1111/exd.12571.

69. Qiang MM, Fowler AJ, Schmuth M, et al. Peroxisome-proliferator-activated receptor (PPAR)- $\gamma$ activation stimulates keratinocyte differentiation. J Invest Dermatol 2004; 123 (2): 305-312. doi: 10.1111/j.0022-202X.2004.23235.x.

70. Sayama K, Komatsuzawa H, Yamasaki K, et al. New mechanisms of skin innate immunity: ASK1-mediated keratinocyte differentiation regulates the expression of b-defensins, LL37, and TLR2. Eur J Immunol 2005; 35 (6): 1886-1895. doi: 10.1002/eji.200526088.

71. Lua X, Liua $\mathrm{T}$, Chena $\mathrm{K}$, et al. Isorhamnetin: A hepatoprotective flavonoid inhibits apoptosis and autophagy via P38/PPAR- $\alpha$ pathway in mice. Biomed Pharmacother 2018; 103: 800-811 doi: 10.1016/j.biopha.2018.04.016.

72. Caroline M, Marco S, Vincent E, et al. 
17,18-Epoxyeicosatetraenoic acid targets PPAR [gamma] and p38 mitogen-activated protein kinase to mediate its anti-inflammatory effects in the lung: Role of soluble epoxide hydrolase. Am J Respir Cell Mol Biol 2010; 43 (5): 564-575. doi: 10.1165/rcmb.2009-0155OC.

73. Dai X, Sayama K, Tohyama M et al. PPAR $\gamma$ mediates innate immunity by regulating the $1 \alpha$, 25-dihydroxyvitamin $\mathrm{D}_{3}$ induced hBD-3 and cathelicidin in human keratinocytes. J Dermatol Sci 2010; 60 (3): 179-186. doi: 10.1016/j.jdermsci.2010. 09.008 .

74. Wang TT, Nestel FP, Bourdeau V, et al. 1,25-Dihydroxyvitamin $\mathrm{D}_{3}$ is a direct inducer of antimicrobial peptide gene expression. J Immunol 2004; 173 (5): 2909-2912. doi: 10.4049/jimmunol. 173.5.2909.

75. Weber G, Heilborn JD, Jimenez CIC, et al. Vitamin $\mathrm{D}$ induces the antimicrobial protein hCAP18 in human skun. J Invest Dermatol 2005; 124(5): 1080-1082. doi: 10.1111/j.0022-202X.2005.23687.x

76. Schauder J, Dorschner RA, Coda AB. Injury enhances TLR2 function and antimicrobial peptide expression through a vitamin D-dependent mechanism. J Clin Invest 2007; 117 (3): 803-811. doi: 10.1172/JCI30142.

77. Angelova-Fischer I, Fernandez IM, Donnadieu MH, et al. Injury to the stratum corneum induces in vivo expression of human thymic stromal lymphopoietin in the epidermis. J Invest Dermatol 2010; 130 (10): 2505-2507. doi: 10.1038/jid.2010.143.

78. Vu AT, Baba T, Chen X. et al. Staphylococcus aureus membrane and diacylated lipopeptide induce thymic stromal lymphopoietin in keratinocytes through the Toll-like receptor 2-Toll-like receptor 6 pathway. J Allergy Clin Immunol 2010; 126 (5): 985-993. doi: 10.1016/j.jaci.2010.09.002.

79. Miyata M, Hatsushika K, Ando T, et al. Mast cell regulation of epithelial TSLP expression plays an important role in the development of allergic rhinitis. Eur J Immunol 2008; 38 (6):1487-1492. doi: 10.1002/eji.200737809.

80. Soumelis V, Reche PA, Kanzler H, et al. Human epithelial cells trigger dendritic cell-mediated allergic inflammation by producing TSLP Nat Immunol 2002; 3 (7): 673-680. doi: 10.1038/ni805.

81. Fort MM, Cheung J, Yen D, et al. IL-25 induces IL-4, IL-5, and IL-13 and Th2-associated pathologies in vivo. Immunity 2001; 15 (6): 985-995 doi: 10.1016/S1074-7613(01)00243-6.

82. Ikeda K, Nakajima H, Suzuki K, et al. Mast cells produce interleukin-25 upon Fc RI-mediated activation. Blood 2003; 101 (9):3594-3596 doi: 10.1182/blood- 2002-09-2817.

83. Havid M, Vestergaard C, Kemp K, et al. IL-25 in atopic dermatitis: a possible link between inflammation and skin barrier dysfunction. J Invest Dermatol 2011; 131 (1): 150-157. doi: 10.1038/jid. 2010. 277.
84. Wang YH, Angkasekwinai P, Lu N, et al. IL-25 augments type 2 immune responses by enhancing the expansion and functions of TSLP-DC-activated Th2 memory cells. J Exp Med 2007; 204 (8): 1837 1847. doi: 10.1084/jem.20070406.

85. Mirchandani AS, Salmond RJ, Liew FY. Interleukin-33 and the function of innate lymphoid cells. Trends in Immunol 2012; 33 (8): 389-396 doi: 10.1016/j.it.2012.04.005.

86. Allakhverdi Z, Smith DE, C0meau MR, et al. The ST2 ligand IL-33 potently activates and drives maturation of human mast cells. J Immunol 2007; 179(4): 2051-2054. doi: 10.4049/jimmunol.179.4. 2051.

87. [88] Novak N, Kruse S, Kraft S, et al. Dichotomic nature of atopic dermatitis reflected by combined analysis of monocyte immunophenotyping and single nucleotide polymorphisms of the interleukin-4/ interleukin-13 receptor gene: The dichotomy of extrinsic and intrinsic atopic dermatitis. J Invest Dermatol 2002; 119 (4): 870-875 doi: 10.1046/j.15231747.2002.00191.x.

88. Hamid Q, Boguniewicz M, Leung DYM. Differential in situ cytokine gene expression in acute versus chronic atopic dermatitis. J Clin Invest 1994; 94(2):870-876 doi: 10.1172/JCI117408.

89. Jeong CW, Ahn KS, Rho NK, et al. Differential in vivo cytokine mRNA expression in lesional skin of intrinsic vs. extrinsic atopic dermatitis patients using semiquantitative RT-PCR. Clin Exp Allergy 2003; 33 (12): 1717-1724. doi: 10.1111/j.13652222. 2003.01827.x.

90. Kato A, Fujii E, Watanabe T, et al. Distribution of IL-31 and its receptor expressing cells in skin of atopic dermatitis. J Dermatol Sci 2014; 74 (3): 229235. doi: 10.1016/j.jdermsci.2014.02.009.

91. Raap U, Wichmann K, Bruder M, et al. Correlation of IL-31 serum levels with severity of atopic dermatitis. J Allergy Clin Immunol 2008; 122 (2): 421-422 doi: 10.1016/j.jaci.2008.05.047.

92. Cheung PFY, Wong1 CK, Ho AWY, et al. Activation of human eosinophils and epidermal keratinocytes by Th2 cytokine IL-31: implication for the immunopathogenesis of atopic dermatitis. Intl Immunol 2010; 22 (6): 453-467 doi: 10.1093/intimm/ dxq027.

93. Sonkoly E, Muller A, Lauerma A, et al. IL-31: A new link between $\mathrm{T}$ cells and pruritus in atopic skin inflammation. J Allergy Clin Immunol 2006; 117 (2): 411-417 doi: 10.1016/j.jaci.2005.10.033.

94. Takaoka A, Arai I, Sugimoto M, et al. Involvement of IL-31 on scratching behavior in NC/Nga mice with atopic-like dermatitis. Exp Dermatol 2006; 15 (3): 161-167 doi: 10.1111/j.1600-0625.2006. 00405.x

95. Grimstad O, Sawanobori Y, Vestergaard C, et al. Anti-interleukin-31-antibodies ameliorate scratching behaviour in $\mathrm{NC} / \mathrm{Nga}$ mice: a model of atopic dermatitis. Exp Dermatol 2009; 18 (1): 35-43. doi: 
10.1111/j.1600-0625.2008.00766.x.

96. Costanzo A, Chimenti MS, Botti E, et al. IL-21 in the pathogenesis and treatment of skin diseases. J Dermatol Sci 2010; 60 (2): 61-66. doi:10.1016/j. jdermsci.2010.08.016.

97. Grewe M, Walther S, Gyufko K, et al. Analysis of the cytokine pattern expressed in situ in inhalant allergen patch test reactions of atopic dermatitis patients. J Invest Dermatol 1995; 105 (3): 407-410 doi: 10.1111/1523-1747.ep12321078.

98. Grewe M, Bruijnzeel-Koomen CA, Schopf E, et al. A role for Th 1 and Th 2 cells in the immunopathogenesis of atopic dermatitis. Immunol Today 1998; 19 (8): 359-361.

99. Malajian D, Guttman-Yassky E. New pathogenic and therapeutic paradigms in atopic dermatitis. Cytokine 2015; 73(2): 311-318. doi: 10.1016/j.cyto. 2014.11.023.

100. Sugimoto T, Ishikawa Y, Yoshimoto T, et al. Iterleukin 18 acts on memory $\mathrm{T}$ helper cells type 1 to induce airway inflammation and hyperresponsiveness in a maive host mouse. J Exp Med 2004; 199 (4): 535-545. doi: 10.1084/jem.20031368

101. Homey B, Steinhoff M, Ruzicka T, et al. Cytokines and chemokines orchestrate atopic skin inflammation. J Allergy Clin Immunol 2006; 118 (1): 178-189 .doi: 10.1016/j.jaci.2006.03.047.

102. Konishi H, Tsutsumi H, Murakami T, et al. IL-18 contributes to the spontaneous development of atopic dermatitis-like inflammatory skin lesion independently of IgE/stat6 under specific pathogen-free condition. Proc Natl Acad Sci USA 2002; 99(17):11340-11345 doi: 10.1073/pnas.152337799

103. Novak N, Kruse S, Poteck J et al. Single nucleotide polymorphisms of the IL-18 gene are associated with atopic eczema. J Allergy Clin Immunol 2005; 115(4):828-833 doi:10.1016/j.jaci.200

104. Higa S, Kotani M, Matsumoto M, et al. Admin-

113. Acad Sci USA 2009; 106 (51): 21795-21800. doi: 10.1073/pnas.0911472106.

114. Trifari S, Kaplan CD, Tran EH, et al. Identification of a human helper $\mathrm{T}$ cell population that has abundant production of interleukin 22 and is distinct from TH-17, TH1 and TH2 cells. Nat Immunol 2009; 10 (8):864-871 doi: 10.1038/ni.1770.

115. Boniface K, Bernard FX, Garcia M, et al. IL-22 inhibits epidermal differentiation and induces proinflammatory gene expression and migration of human keratinocytes. J Immunol 2005; 174 (6): 3695-3702. doi: 10.4049/jimmunol.174. 6.3695.

116. Nograles KE, Zaba LC, Shemer A, et al. IL-22producing "T22" T cells account for upregulated IL-22 in atopic dermatitis despite reduced IL-17producing TH17 T cells. J Allergy Clin Immunol 2009; 123 (6): 1244-1252. doi: 10.1016/j.jaci.2009. 03.041 .

117. Kim SH, Hong JH, Lee YC. Ursolic acid, a potential PPARg agonist, suppresses ovalbumin-induced airway inflammation and Penh by down-regulation istration of anti-interleukin 18 antibody fails to inhibit development of dermatitis in atopic dermatitis-model mice NC/Nga. Br J Dermatol 2003; 149 (1): 39-45. doi: 10.1046/j.1365-2133.2003. 05406. $\mathrm{X}$.

105. Jin H, Oyoshi MK, Le Y, et al. IL-12R is essential for epicutaneous sensitization and allergic skin inflammation in human and mice. J Clin Invest 2009; 119 (1): 47-60. doi: 10.1172/JCI32310.

106. Mizutani H, Mineoka RT, Nakamura N, et al. Serum IL-21 levels are elevated in atopic dermatitis patients with acute skin lesions. Allergol Intl 2017; 66 (3): 440-444. doi: 10.1016/j.alit.2016.10.010.

107. Thepen T, Langeveld-Wildschut EG, Bihari IC, et al. Biphasic response against aeroallergen in atopic dermatitis showing a switch from an initial $\mathrm{TH} 2$ response to a TH1 response in situ: An immunocytochemical study. J Allergy Clin Immunol 1996; 97 (3): 828-837.

108. Koga C, Kabashima K, Shiraishi N, et al. Possible pathogenic role of Th17 Cells for atopic dermatitis. J Invest Dermatol 2008; 128 (11): 2625-2630. doi:10.1038/jid.2008.111.

109. Maa L, Xueb HB, Guanc XH, et al. Possible role of Th17 cells and IL-17 in the pathogenesis of atopic dermatitis in northern China. J Dermatol Sci 2012; 68 (1): 66-67. doi:10.1016/j.jdermsci.2010.08.016

110. MilovanovicM, Drozdenko D, Weise C, et al. Interleukin-17A promotes IgE production in human B cells. J Invest Dermatol 2010; 130 (11): 2621-2628. doi: 10.1038/jid.2010.175.

111. Duhen T, Geiger R, Jarrossay D, et al. Production of interleukin 22 but not interleukin 17 by a subset of human skin-homing memory $\mathrm{T}$ cells. Nat Immunol 2009; 10 (8):857-863. doi: 10.1038/ni.1767.

112. Fujita H, Nograles KE, Kikuchi T, et al. Human Langerhans cells induce distinct IL-22-producing $\mathrm{CD}^{+} \mathrm{T}$ cells lacking IL-17 production. Proc Natl IL-5, IL-13, and IL-17 in a mouse model of allergic asthma. Eur J Pharmacol 2013; 701 (1-3): 131-143. doi: 10.1016/j.ejphar.2012.11.033.

118. Jung Y, Kim JC, Park NJ, et al. Eupatilin, an activator of PPARa, inhibits the development of oxazolone-induced atopic dermatitis symptoms in Balb/c mice. Biochemi Biophys Res Comm 2018; 496 (2): 508-514. doi: 10.1016/j.bbrc.2018.01.098

119. Hatano Y, Man MQ, MD, Uchida Y, et al. Murine atopic dermatitis responds to peroxisome proliferator-activated receptors $\alpha$ and $\beta / \delta$ (but not $\gamma$ ) and liver X receptor activators. J Allergy Clin Immunol 2010; 125 (1): 160-169. doi: 10.1016/j.jaci.2009.06. 049

120. Aioi A, Tonogaito H, Suto H, et al. Impairment of skin barrier function in NC/Nga Tnd mice as a possible model for atopic dermatitis. Br J Dermatol 2001; 144 (1): 12-18. doi: 10.1046/j.1365-2133. 2001. 03946.x.

121. Matsuda H, Watanabe N, Geba GP, et al. Development of atopic dermatitis-like skin lesion with IgE 
hyperproduction in $\mathrm{NC} / \mathrm{Nga}$ mice. Intl Immunol 1997; 9 (3):461-466. doi: 10.1093/intimm/9.3.461.

122. Nishino R, Fukuyama T, Watanabe Y, et al. Significant upregulation of cytokine secretion fromT helper type 9 and 17 cells in a NC/Nga mouse model of ambient chemical exposure-induced respiratory allergy. J Pharmacol Toxicol Methods 2016; 80: 35-42. doi: 10.1016/j.vascn.2016.04.009.

123. Iwasaki T, Tanaka A, Matsuda H. Atopic NC/Nga mice as a model for allergic asthma: Cytokine profiles and eosinophil productivity of bone marrow. J Vet Med Sci 2001; 63 (4): 471-474. doi: 10.1292/jvms.63.471.

124. Chiba T, Takeuchi S, Esaki H, et al Topical application of PPAR $\alpha$ (but not $\beta / \delta$ or $\gamma$ ) suppesses atopic dermatitis in NC/Nga mice. Allergy 2012; 67 (7): 936-942. doi: 10.1111/j.1398-9995.2012. 02844.x.

125. Karuppagounder V, Somasundaram A, Thandavarayan RA, et al. Tannic acid modulates $\mathrm{NF \kappa B}$ signaling pathway and skin inflammation in $\mathrm{NC} / \mathrm{Nga}$ mice through PPARc expression. Cytokine 2015; 76 (2): 206-213. doi: 10.1016/j.cyto.2015.05. 016. 